\title{
Digital Transformation and Improvement of Business Processes with Internet of Things: A Maturity Model for Assessing Readiness
}

\author{
Christoph Stoiber \\ University of Regensburg \\ christoph.stoiber@stud.uni-regensburg.de
}

\author{
Stefan Schönig \\ University of Regensburg \\ stefan.schoenig@ur.de
}

\begin{abstract}
Companies of all industrial sectors are increasingly integrating Internet of Things (IoT) technology into their processes to realize a data-driven transformation of their businesses. The generation and use of comprehensive process data in real-time and the connection of process entities enables an improvement and beneficial redesign of business processes of all kinds. However, a goal-oriented exploitation of IoT technology for digital transformation and Business Process Improvements (BPI) is challenging due to the complexity of integrating IoT into existing processes. Companies require appropriate guidance to evaluate and scope their initiatives regarding IoT-based BPI. We therefore propose a holistic IoT-based BPI Maturity Model that assists organizations to determine their current state and get assistance to optimize or develop specific capabilities. This paper provides an overview about the structured development process of the maturity model comprising an extensive literature review and a six-round Delphi study.
\end{abstract}

\section{Introduction}

The Internet of Things (IoT) constitutes a technological revolution that has a disruptive impact on a wide range of social, technological, and economic areas. For industrial companies, IoT can be seen as both a digital innovation opportunity as well as a digital transformation opportunity [1]. In this context, digital transformation is characterized by enabling connectivity, collecting data, and therefore using digital technology to redefine a value proposition and to change the identity of the organization [2]. As IoT offers the capabilities to enhance connectivity and collect data, it is a main technology to enable digital transformation [3]. One major lever to transform the organization is IoT-based Business Process Improvement (BPI) which changes the way, companies are doing their businesses [4]. However, a structured and goal-oriented integration of IoT technology to achieve BPI constitutes a major challenge for companies. Most companies already have mature and complex process landscapes, IT system architectures, organizational structures, and corporate cultures that often prevent an easy implementation of disruptive technologies, such as IoT [5]. In addition, organizations are often unable to determine the status quo of their fitness regarding IoT-based BPI [6] and therefore are incapable in developing a substantive action plan for performing IoT projects [7]. Furthermore, the design of strategic roadmaps to enhance the competitive position requires a continuous analysis of the status quo [8]. Maturity Models (MM) have proven to be a useful management tool to guide organizations in the identification, prioritization, and development of relevant capabilities [9]. Especially in the area of Industry 4.0 and IoT, MMs have been recognized as a topic of great interest with increasing numbers of approaches from academia and industry [10]. However, with a share of only $6 \%$, a very limited number of IoT-related MM publications also incorporates the topic of business processes into their model design [11]. Moreover, the aspect of designing a MM to evaluate the capabilities to effectively exploit IoT for digital transformation and BPI has not been considered at all. The paper at hand therefore aims at filling this research gap by addressing the following research questions:

- RQ1: How can industrial organizations assess their readiness to effectively exploit IoT technologies for the digital transformation and improvement of their business processes?

- $\quad$ RQ 2: How can industrial organizations prioritize actions to develop and improve capabilities relevant for the digital transformation and improvement of their processes by exploiting IoT technologies?

To address these research questions, we developed a prescriptive $\mathrm{MM}$ for assessing readiness to effectively exploit IoT technology for BPI, in the further course the "IoT-based BPI MM". The IoT-based BPI MM includes 21 capability dimensions representing action fields for organizations. For each of these capability dimensions, we formulated individual capabilities arranged in four capability levels. Furthermore, we formulated five maturity levels that represent the overall assessment of the organization regarding their fitness to effectively exploit IoT for BPI. In our approach, each maturity level 
is aligned to a set of capability levels that need to be achieved. A translation metric indicates, which capability levels are relevant to accomplish a specific maturity level. To obtain a rigorous and evaluated MM, it has been developed according to the proved design framework of Becker et al. [8].

The remainder of this article is structured as follows. Section 2 presents the theoretical background of the research area including related work. In section 3 , the underlying research methodology and the deployed development process are described in detail. The development of the initial MM is outlined in section 4, while the refinement including an extensive Delphi study is presented in section 5. A summary of the main contributions, existing limitations, and future research topics are depicted in section 6.

\section{Theoretical Background}

\subsection{Internet of Things meets Business Process Improvement}

The term IoT can be outlined as a network that connects uniquely identifiable things to the internet. Through the exploitation of unique identification and sensing, information about the thing can be collected and the state can be changed from anywhere, anytime, by anything [12]. Hereof the term thing describes the creation of a ubiquitous presence of objects of all kinds, equipped with sensors and actuators. Further, the term internet refers to the ability of the things to build a network of interconnected objects based on designated network technologies. Beyond, the IoT paradigm incorporates a semantic view that refers to the ability of uniquely identifying things and storing, processing, and exchanging data [13]. The transformation of analog information into digital data, which can be processed worldwide in real-time, can have major impacts on business models and processes [14]. This impact is highly relevant for enterprises following a businessoriented view of their organization and all including operations. By implementing IoT technology, enterprises can digitally transform and therefore improve their business processes. This is highly relevant, as redesigning and therefore improving business processes has been one of the most relevant topics in both research and business environment and is considered as one of "the most important and common titles in both literature and applications" [15]. To effectively integrate IoT applications into business processes and therefore realize beneficial BPI, specific capabilities are required within adopting organizations.

\subsection{Capabilities and Maturity Models}

According to Barney's [16] resourced-based view, organizations can be comprehended as configurations of different resources. Therefore, competitive advantage and long-term performance enhancement is accomplished by providing valuable, unique, inimitable, and non-substitute resources that consist of assets and capabilities [17, 18]. While assets can be seen as resource endowments the organization has accumulated, capabilities enable these assets to be deployed advantageously [19]. Capabilities cannot be given a monetary value and are so deeply embedded in the organizational routines and practices that they cannot be traded or imitated [20]. In this paper, capabilities will be defined as complex bundles of skills, accumulated knowledge, and systems exercised through organizational processes, that enable firms to coordinate activities and make use of their assets [20]. They enable the organization to perform certain activities to achieve a particular outcome [21]. It is therefore highly relevant for organizations to have an objective view on capabilities and to assess their current state. In that respect MMs have extensively been used to $i$ ) assess the capabilities of an organization with regards to a certain discipline, ii) provide a base for benchmarking with competitors, and iii) guide an organization into acquiring the needed capabilities to improve that discipline [22]. Depending on which of the goals to focus on, there are three types of models that have been widely utilized as a management tool. Descriptive MMs assessing the status quo, comparative MMs providing benchmarking, and prescriptive MMs enabling the development of roadmaps for improving the maturity level [9]. MMs are often represented as matrices with distinct maturity levels on the one axis and capability dimensions on the other one [23].

One of the first MMs was the Capability Maturity Model (CMM) that has been designed for assessing the maturity of software development processes [24]. It has been adopted for many other disciplines leading to a widespread of distinct MMs suffering from overlaps, contradictions, and lack of standardization. To create a standardized framework model that can be used by organizations regarding enterprise-wide process improvement, the Capability Maturity Model Integration (CMMI) project was initiated [25]. Based on the CMMI, many further MMs have been developed for a variety of different research areas.

\subsection{Related Work}

To the best of the authors' knowledge, there has not been any MM research that focuses on the organizations' capability maturity for effectively 
exploiting IoT for goal-oriented BPI. However, several MMs have been developed to assist organizations in understanding their maturity level regarding IoT, Industry 4.0, or BPM topics.

For example, Jæger and Halse [26] proposed an IoT maturity scorecard that can assist companies in the manufacturing industry in adopting IoT technologies. Similarly, Tan et al. [27] developed a MM with a special focus on the manufacturing shop-floor environment. Further, Serral et al. [22] concentrated on the retail industry and provided a MM to assess the as-is situation and give advice on future actions for a successful IoT adoption. Other MMs even applied a broader technological view and incorporated other technologies regarding Industry 4.0 [28]. Klötzer and Pflaum [29] developed a MM concerning the digital transformation of companies within the manufacturing industry's supply chain. Moreover, some publications do not specially focus on industrial branches but on the maturity of organizational disciplines regarding IoT or Industry 4.0, such as the IT system landscape [30]. Regarding BPM and BPI, the topic's second focus, there has already been prior MM research. Rosemann and De Bruin developed a BPM MM which facilitates the assessment of basic BPM capabilities [31]. Furthermore, Tarhan et al. provided a wide overview of existing MMs that are addressing general BPM capabilities [32]. In addition, Koetter et al. developed a MM for business process optimization [33].

With considering capabilities for effectively exploiting IoT for digital transformation of business processes and goal-oriented BPI, the work at hand addresses a new scope.

\section{Methodology and Development Process}

Most of the MM that have been investigated within this research project have been developed according to the frameworks of either De Bruin et al. [21] or Becker et al. [8]. As De Bruin et al. [21] provided a general framework for MM development, it can be adapted for any MM instance. However, we have chosen the structured procedure of Becker et al. [8] as it provides a more detailed procedure allowing the development of a theoretically sound and rigorously tested MM. The development process consists of eight phases based on design science research principles by Hevner et al. [34]. These eight phases can be arranged in two sections, namely the Design and Development section, and the Transfer and Evaluation section [18]. The work at hand will focus on the first section, while the second section will be provided in future research by means of an extensive industrial use case. Figure 1 shows the development process including the comprised phases.
Phase 1, Problem definition, describes the motivation for developing the MM including existing conditions for its application and the intended benefits. Also, the identification of the problem relevance is clarified in this phase. Within this work, these topics are addressed in section 1, where the motivation and relevance of IoT-based BPI are outlined. Organizations require assistance for assessing their capabilities and guidance for deriving roadmaps to build up or improve capabilities. The formulated RQs summarize the objectives of the model development.

The second Phase 2, Comparison of existing MMs, substantiates the need for the development of a new MM and therefore reveals an existing research gap. This is described in subsection 2.3.

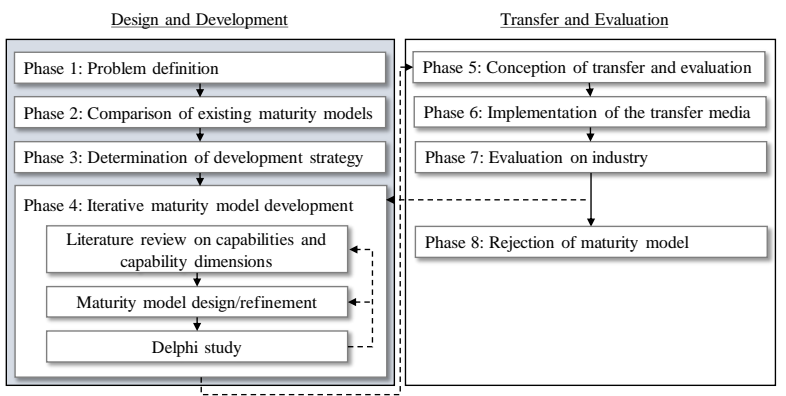

Figure 1. Development Process

Phase 3, Determination of the development strategy, defines the basic approach for developing the MM. According to Becker et al. [8], there are four strategies, namely i) design of a new model, ii) enhancement of an existing model, iii) combination of models to form a new one, and $i v$ ) the transfer of existing models to new application domains. For the work at hand, the strategy of designing a new model has been chosen, as there are no existing MMs that are sufficiently addressing the formulated RQs. Also, this gives the opportunity to flexibly design the MM according to the requirements of the topic. However, also insights and components of already existing models have been used and enhanced.

The fourth Phase 4, Iterative MM development, depicts the actual model creation steps that lead to the final MM. For the IoT-based BPI MM, this is performed in a multi-methodological approach consisting of two steps. First, an initial MM is created based on the findings of an extensive literature review on existing MMs of both research disciplines IoT and BPM. Subsequently, the initial model is refined by conducting a Delphi study with experts from industry and academia. Both development steps will be presented in sections 4 and 5.

As mentioned, Phases 5 to 8, which constitute the Transfer and Evaluation of the MM, will not be 
addressed within this work. These phases will be conducted in future research.

\section{Initial Maturity Model Development}

\subsection{Maturity Model Design}

In most cases, MMs are designed as matrices that include capability dimensions on the one axis and maturity levels on the other axis. Within these MMs, to accomplish a specific maturity level, it is necessary to achieve all capabilities that are stated for the respective maturity level. For the MM at hand, however, we use a staged MM design approach. This means that we first arrange the capabilities of all dimensions along four capability levels in the so-called capability matrix. Increasing capability level refers to increasing complexity and relevance of the capability dimension. To accomplish a certain maturity level, an organization must achieve particular capability levels for each capability dimension. This staged MM approach enables a weighting and emphasis of importance for individual capability dimensions. To illustrate which capability levels are required for each maturity level a translation metric is used.
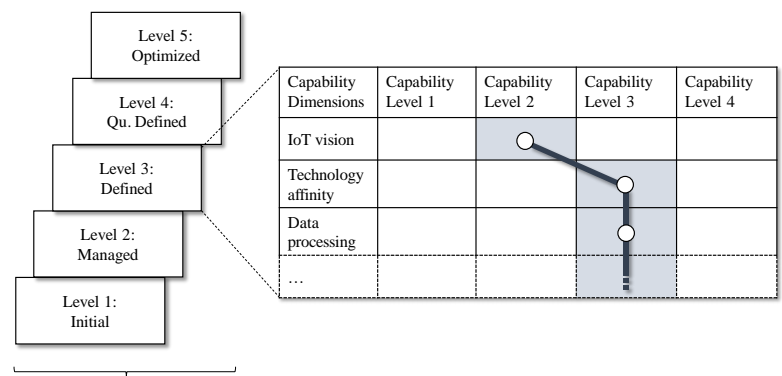

Maturity Levels

\section{Figure 2. Translation Metric Example}

Figure 2 shows the relation between maturity levels on the left, and the capability matrix on the right-hand side. To accomplish, e.g., maturity level 3, an organization must achieve capability level 3 for the capability dimensions technology affinity, and data processing, while capability level 2 is sufficient for dimensions IoT vision. Each capability level then contains individual capabilities for each dimension. We defined five maturity levels Initial, Managed, Defined, Quantitatively Managed, and Optimized referring to the levels of the CMMI [25]:

- Maturity Level 1: Initial

IoT technology and BPM is hardly existent within the organization. Integration of IoT technology into business processes is not performed.

- Maturity Level 2: Managed
Awareness for the benefits of IoT technology is present. Basic IoT technology is integrated into actively structured and managed processes.

- Maturity Level 3: Defined

Multiple IoT applications are present, and BPM is actively performed. IoT technology is used to support process execution and realize basic BPIs.

- Maturity Level 4: Quantitatively Managed Strategic planning of IoT projects and wellestablished integration of IoT technology into business processes. IoT applications enable beneficial BPI.

- Maturity Level 5: Optimized

IoT technology is used to improve and redesign business processes of all kinds. Structured and strategic organization-wide procedures to achieve advanced IoT-based BPI.

\subsection{Literature Review}

For the creation of an initial IoT-based BPI MM, it is necessary to identify potential capability dimensions and individual capabilities that are appropriate to represent all aspects that organizations need to assess. Therefore, an extensive literature review on existing MMs of both research areas IoT and BPM has been conducted. In addition, publications that illustrate IoT and BPM respectively BPI capabilities have been investigated. As the exploitation of IoT for BPI requires capabilities regarding the management of IoT technology and the organization's BPM, this will give an outlook on all relevant aspects. The literature review has been performed according to the structured procedure proposed by vom Brocke et al. [35].

At first the search strings ("IoT" $O R$ " $C P S$ " $O R$ "BPI" OR "BPM") AND ("maturity model" $O R$ "capability maturity model") and ("IoT" OR "CPS" OR "BPI" OR "BPM") AND ("capabilit*”) as well as the written-out forms have been formulated. The abbreviation CPS (Cyber-Physical Systems) is also incorporated, as it is often used as a synonym for IoT. To consider preferably all relevant journals and conference proceedings of the research area, ACM Direct Library, AISeL, IEEE Xplore, ScienceDirect, Scopus, and Springer Link have been queried.

For the title, abstract, and keyword queries with the first search string, 16 papers related to IoT MMs and 18 papers related to BPI or BPM MMs have been found after removing duplicates. While analyzing the publications, 272 capabilities have been identified that were coded and clustered in 26 capability dimensions. A query with the second search string added 19 papers regarding IoT capabilities and 27 papers regarding BPI or BPM capabilities. Another 89 further capabilities could be worked out and were clustered in 11 
supplementary capability dimensions. In total, 361 capabilities were derived from the literature review, clustered in 37 capability dimensions. After discarding redundancies and summarizing similar ones, 25 capability dimensions were finally derived that comprise 100 capabilities in four different capability levels. The formulated capability dimensions are now briefly outlined in the following subsection.

\subsection{Capability Dimensions of the Initial MM}

The organization's strategy and the management's commitment towards IoT technology are important factors for an effective selection and execution of IoT projects. Structured decision making is a key factor to evaluate project options and to decide on the most beneficial ones. Also, the organization's openness for changing existing processes is highly relevant. Therefore, the capability dimensions IoT vision \& roadmap, structured decision making [36], management support, and willingness to adapt business processes are considered for the initial MM [6].

The prevailing organizational culture and ethics are enormously relevant when it comes to introducing new technologies such as IoT [18]. Especially the organization's attitude towards change of any kind is a crucial factor as IoT projects might suffer from negative reservations. Furthermore, the existence of methods and capabilities regarding business improvement plays a major role. As most IoT projects are carried out by interdisciplinary teams consisting of different groups of experts, a collaboration must be performed. These topics comprise the capability dimensions degree of technology affinity, the existence of a continuous improvement culture [6], as well as an interdisciplinary and interdepartmental collaboration [37].

The complexity, maturity, and value propositions of IoT applications highly depend on the skills and competences of the responsible personnel. If knowledge about IoT technology is not present within an organization, only basic technologies with limited benefits can be implemented. Also, the transformation and improvement of existing business processes requires skilled experts. These skills and the accumulated knowledge must be managed, maintained, and distributed within the organization. Therefore, the capability dimensions knowledge management, IoT competences along employees, dedicated teams for IoT, and dedicated teams for BPM are introduced [22].

Further, the technical infrastructure represents an important area that includes several capabilities regarding the organizations' ability to transmit and process data. The capability dimensions networking technologies and enterprise software systems depict a highly relevant aspect regarding the integration of IoT technology into business processes [38].

IoT devices are generating massive amounts of event data that can be used within business processes. To do so, a mature data management is required comprising data analytics \& interpretation, data integration and privacy capability dimensions [39].

As the redesign, transformation, and improvement of business processes are topics of BPM research, the organization's alignment towards business process orientation as well as the implemented methods of managing business processes is highly important [40]. Further, the definition and usage of metrics to track process performance and the existence of proper process documentation are necessary to realize effective BPI [38]. These capability dimensions are crucial to outline specific BPM-related capabilities.

Another focus area for capability dimensions is the characterization of present IoT applications itself. It describes the maturity of the implemented IoT applications and the technological characteristics. First, the adopted IoT architecture is highly relevant as it describes the capabilities of the IoT application to create value and improve businesses [39]. Moreover, the details of the used IoT technologies and their complexity are important [22]. This is described within the capability dimension IoT technology, including the technical details of the solution that are already present within the organization.

Furthermore, the degree to which IoT is integrated in the design, analysis, configuration, improvement, and evaluation of business processes must be assessed [22]. This incorporates the capability dimensions system integration, behavioral and organizational impact, as well as functional and operational impact [39]. System integration refers to organization's capabilities to effectively use IoT technology within executed business processes. This requires the creation of interfaces and the standardization of data formats. Also, IoT applications have an impact on several facets of the process perspectives [41]. The behavioral perspective refers to the process sequences and workflows, whereas the organizational perspective focuses on the selection of personnel that is involved in the process execution and monitoring. The functional perspective includes the concrete process steps, activities, and events which can all be influenced by IoT technologies. Finally, most of the processes, especially in the manufacturing industry, comprise several facilities, machines, tools, software applications or items which can be described as the operational perspective [41].

For all these capability dimensions, we formulated a set of corresponding capabilities, ordered by increased influence on achieving a beneficial topic of IoT-based BPI. This resulted in a capability matrix with 100 
capabilities along 25 capability dimensions and four capability levels. Hereof, capability level 1 has the lowest positive influence on IoT-based BPI, while level 4 has the highest. Due to the limited scope, a detailed description of the capabilities has been omitted. However, the final MM including all details is illustrated in section 6 .

\section{Maturity Model Refinement}

\subsection{Delphi Study Setup}

To obtain a rigorously developed and evaluated MM, we performed a structured six-round Delphi study to refine the initial MM proposal. A Delphi study is an iterative method to solicit information about a specific topic through the completion of a number of surveys [42]. It has been widely used to combine expert knowledge and find group consent for complex issues that lack empirical evidence [42]. Research experiences revealed that Delphi studies generally result in a higher quantity and quality of idea and knowledge contribution than other group-decision methods [43]. Further, Delphi studies are highly present in information systems research and especially in the research of MMs [42]. The general study process includes the selection of experts with different backgrounds to minimize bias. The experts do not get introduced to each other, which leads to more creative outcomes and reduces conflicts within the group as well as group pressure [43]. The experts are asked to rate, indicate, or validate specific topics in several rounds. After each round, the results of all participants are consolidated and used for model refinement. By iteratively adjusting the model, eventually a final consent can be achieved. According to existing publications about Delphi studies, 10-18 participants represent an appropriate number [42].

Table 1. Expert Panel Description

\begin{tabular}{ll}
\hline Expert panel characteristic & Number of experts \\
\hline Affiliation & \\
\hline Industry & 10 \\
Academia & 5 \\
\hline Nationality & \\
\hline Germany & 7 \\
Sweden & 2 \\
Netherlands & 1 \\
USA & 3 \\
China & 2 \\
\hline Years of experience & \\
\hline$<5$ years & 2 \\
5-14 years & 3 \\
$\geq 15$ years & 10 \\
\hline Expertise & \\
Internet of Things & 9 \\
Business Process Management & 8 \\
Maturity Models & 5 \\
IT Project Management & 5 \\
\hline
\end{tabular}

By forming an expert panel of 15 persons, we conform with recommendations. Within the panel, 10 experts are selected from organizations ranging from medium-sized companies to multinational corporations in the chemical and manufacturing industry (see Table 1). The remaining 5 experts are academical researchers in the fields of IoT and BPM. To minimize regional influences, we selected experts from Germany, Sweden, Netherlands, USA, and China. As technological knowledge may differ between persons who have rather recently graduated from educational establishments and persons with many years of experience, we selected experts with different years of working experiences. Eventually, 2 experts have less than 5 years' experience, 3 experts have working experience between 5 and 14 years, while 10 experts have experiences of 15 years or more. Finally, as the survey topic includes several research areas, we included persons with expertise in IoT, BPM, MMs, and IT project management. All experts have at least a bachelor's degree while including 6 female and 9 male persons. Having selected the expert panel, the actual survey has been conducted in six rounds. Figure 3 shows the applied Delphi process including the tasks and information flows between both parties, the research team or facilitator and the expert panel. The capability dimensions and capabilities from section 4.3. served as an input for the study.

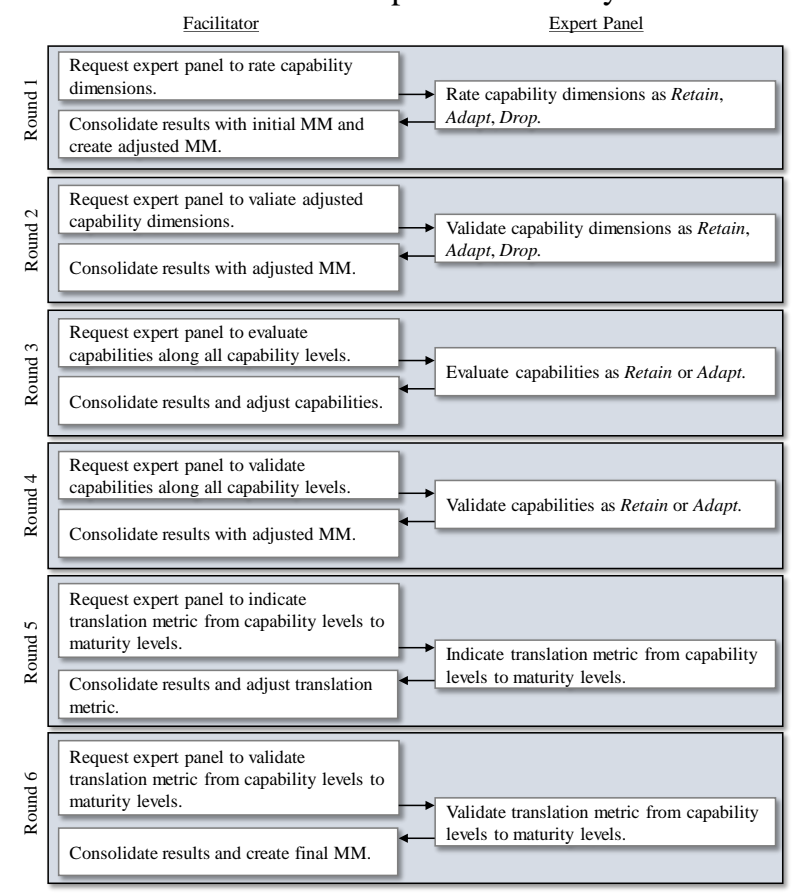

Figure 3. Delphi Study Process

In Round 1, the expert panel was requested to rate the formulated capability dimensions as Retain, Adapt, or Drop. In addition, the experts could also suggest new capability dimensions. The results of round 1 were 
analyzed and consolidated by using a systematic decision tree (see Figure 4), that has already been proven in prior Delphi studies [22]. A capability dimension was only dropped, if more than $60 \%$ of the experts agreed on this option. No adaptions were considered, if the percentage to retain was at least $80 \%$, while minor adaptions were performed for a retain rate between $60 \%$ and $80 \%$. Major adaptions were needed if the retain rate was below $40 \%$ or at least $50 \%$ of the experts agreed on the option to adapt a specific capability dimension. The last possible outcome was when the percentage to retain was at least $40 \%$ and the percentage to adapt was at least $50 \%$ at the same time indicating that there has been a lack of unity in opinion. In Round 2, the experts were requested to validate the adjusted capability dimensions, again by using the options Retain, Adapt, or Drop. This was followed by another consolidation phase. In Round 3, the expert panel was requested to evaluate the capabilities along the four capability levels with Retain or Adapt.

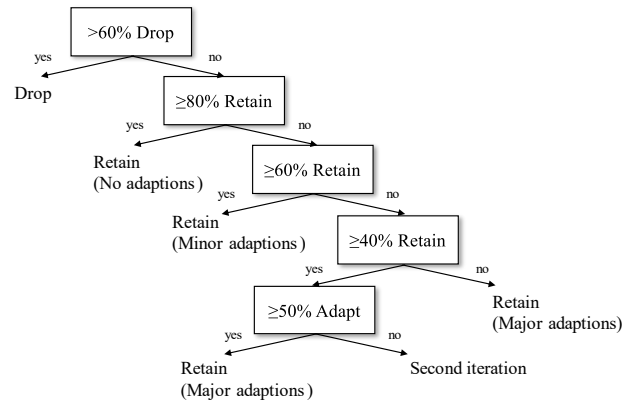

Figure 4. Decision Tree

For a retain rate of at least $80 \%$, no adaptions were considered. Elsewise, for a retain rate between $60 \%$ and $80 \%$ minor changes were performed, while major adaptions were necessary for a retain rate below $60 \%$. In Round 4, the consolidated capabilities were validated by using the same logic. As with rounds 1 to 4 the capability dimensions, and the respective capabilities have been evaluated, Round 5 and 6 were about creating the translation metric. The expert panel was requested to indicate the translation metric from capability levels to maturity levels. For each of the five maturity levels, the experts needed to indicate the required capability level of every capability dimension. For all six rounds, the participants could add additional comments regarding their indications. The facilitators then consolidated all results by choosing the most frequently selected value for each capability dimension and maturity level. If two or more values were chosen equally often, the median of all values was selected as it considers the trend within all indications. The created translation metric was then validated in Round 6, concluding in a final consolidation. After the final round, a discussion with all experts individually helped to get feedback and gain insight into the motivations and background of the individual decisions.

\subsection{Delphi Study Results}

In Round $\mathbf{1}$ and $\mathbf{2}$, the expert panel rated all capability dimensions. The results of both individual rounds have been consolidated by using the systematic decision tree (see Figure 4). In total, 13 capability dimensions were retained without changes. Further, 5 capability dimensions were considered for minor changes while 2 capability dimensions were majorly adapted. From the initial set of 25 dimensions, 5 were dropped completely, whereas 1 capability dimension could be added. For the final set of capability dimensions, the individual capabilities have been formulated. In Round $\mathbf{3}$ and $\mathbf{4}$, the expert panel evaluated the capabilities as Retain or Adapt. Based on the results of both rounds, 29 capabilities were considered for minor changes, 14 for major changes, while 41 were not changed at all. As after rounds 1 to 4 , the main structure of the MM has been evaluated, in Round 5 and 6, the translation metric from capability levels to maturity levels was created. Therefore, the expert panel indicated the required capability level of each capability dimension for achieving a specific maturity level. For maturity levels 1 and 2, there has been a broad conformity along the expert panel. However, for maturity levels 3 and 4, as the indications have not been unambiguous resulting in using the median. Especially, the capability dimensions continuous improvement culture, knowledge management, and alignment \& methods showed a wide distribution of indicated values. This shows the disagreement of the expert panel and the associated uncertainty regarding the relevance of these dimensions. In general, academic experts tended to emphasize the importance of technical dimensions related to the infrastructure or data processing capabilities of organizations. On the other hand, industrial experts underlined the importance of dimensions regarding the organizations' culture, ethics, employee competences, and strategical leadership. Any other tendencies regarding the results and the expert background could not be recognized. In general, the Delphi study helped to effectively refine the initial MM.

\section{Final IoT-based BPI MM}

The final IoT-based BPI MM consists of three main components, the capability matrix (see Figure 2), the translation metric (see Table 3), and the maturity level description illustrated in section 4.1. The final capability matrix consists of 21 capability dimensions clustered in 
7 focus areas for improved structure. The translation metric determines, which capabilities, are required for each dimension to accomplish a specific maturity level.

Table 2. Capability Matrix

\begin{tabular}{|c|c|c|c|c|c|}
\hline \multirow[b]{2}{*}{ Focus Area } & \multirow[b]{2}{*}{ Capability Dimension } & \multicolumn{4}{|c|}{ Capability Levels } \\
\hline & & Level 1 & Level 2 & Level 3 & Level 4 \\
\hline \multirow{2}{*}{$\begin{array}{l}\text { Strategy \& } \\
\text { Leadership }\end{array}$} & IoT vision & $\begin{array}{l}\text { Management has closed } \\
\text { attitude towards IoT. }\end{array}$ & $\begin{array}{l}\text { Management understands IoT } \\
\text { and its value propositions. }\end{array}$ & $\begin{array}{l}\text { Management is setting up a } \\
\text { detailed IoT vision and } \\
\text { roadmap. }\end{array}$ & $\begin{array}{l}\text { Management sees IoT as a } \\
\text { crucial technology to gain } \\
\text { competitive advantage. }\end{array}$ \\
\hline & Decision making & $\begin{array}{l}\text { No decision making about } \\
\text { selecting IoT technology. }\end{array}$ & $\begin{array}{l}\text { Selection based on best- } \\
\text { practices. }\end{array}$ & $\begin{array}{l}\text { Selection based on external } \\
\text { and internal expert consulting. }\end{array}$ & $\begin{array}{l}\text { Quantitative and qualitative } \\
\text { methods and assessments. }\end{array}$ \\
\hline \multirow{3}{*}{$\begin{array}{l}\text { Culture, Ethics \& } \\
\text { Behavior }\end{array}$} & Technology affinity & $\begin{array}{l}\text { Reservations or rejection } \\
\text { of new technologies. }\end{array}$ & $\begin{array}{l}\text { Open to learn about new } \\
\text { technologies and its potentials. }\end{array}$ & $\begin{array}{l}\text { Active searching and learning } \\
\text { about new technologies. }\end{array}$ & $\begin{array}{l}\text { Eager for life-long-learning } \\
\text { about new technologies. }\end{array}$ \\
\hline & $\begin{array}{l}\text { Continuous improvement } \\
\text { culture }\end{array}$ & $\begin{array}{l}\text { No intrinsic motivation } \\
\text { for improvements. }\end{array}$ & $\begin{array}{l}\text { Basic incentive systems to } \\
\text { uncover improvement } \\
\text { potentials. }\end{array}$ & $\begin{array}{l}\text { Adaption of further methods, } \\
\text { e.g. PDCA, Kaizen, or Six } \\
\text { Sigma. }\end{array}$ & $\begin{array}{l}\text { A fundamental continual } \\
\text { improvement process is } \\
\text { implemented. }\end{array}$ \\
\hline & $\begin{array}{l}\text { Interdisciplinary, } \\
\text { interdepartmental } \\
\text { collaboration }\end{array}$ & $\begin{array}{l}\text { No explicit collaboration } \\
\text { between different } \\
\text { departments. }\end{array}$ & $\begin{array}{l}\text { Communication, coordination, } \\
\text { and awareness are present, but } \\
\text { treated opportunistically. }\end{array}$ & $\begin{array}{l}\text { Decentralized coordination } \\
\text { and shared knowledge, } \\
\text { mainly through group } \\
\text { artifacts. }\end{array}$ & $\begin{array}{l}\text { Tacit knowledge is shared } \\
\text { through ideas, opinions, and } \\
\text { experiences. }\end{array}$ \\
\hline \multirow{4}{*}{$\begin{array}{l}\text { People, Skills \& } \\
\text { Competences }\end{array}$} & Knowledge management & $\begin{array}{l}\text { Knowledge is created via } \\
\text { training. No formal } \\
\text { knowledge management } \\
\text { practices are present. }\end{array}$ & $\begin{array}{l}\text { Knowledge-sharing activities } \\
\text { are actively encouraged while } \\
\text { the benefits are observed and } \\
\text { monitored. }\end{array}$ & $\begin{array}{l}\text { Enterprise-wide knowledge } \\
\text { management system has been } \\
\text { established and knowledge is } \\
\text { reused at project levels. }\end{array}$ & $\begin{array}{l}\text { Knowledge sharing becomes } \\
\text { an organizational culture and } \\
\text { knowledge is a critical asset. }\end{array}$ \\
\hline & $\begin{array}{l}\text { IoT competences along } \\
\text { employees }\end{array}$ & $\begin{array}{l}\text { No experiences with IoT } \\
\text { technologies. }\end{array}$ & $\begin{array}{l}\text { Initial experience with IoT } \\
\text { based on past and isolated } \\
\text { current projects. }\end{array}$ & $\begin{array}{l}\text { Internal and external IoT } \\
\text { experiences and knowledge } \\
\text { exchange with experts. }\end{array}$ & $\begin{array}{l}\text { Employees are experienced in } \\
\text { IoT through targeted } \\
\text { trainings. }\end{array}$ \\
\hline & Dedicated teams for IoT & $\begin{array}{l}\text { No internal structures or } \\
\text { specialist departments. }\end{array}$ & $\begin{array}{l}\text { IoT projects are carried out by } \\
\text { employees who have been } \\
\text { trained. }\end{array}$ & $\begin{array}{l}\text { Design, planning, } \\
\text { implementation, and } \\
\text { maintenance is handled by } \\
\text { dedicated teams. }\end{array}$ & $\begin{array}{l}\text { IoT core competence centers } \\
\text { exist that are designed for the } \\
\text { corresponding company } \\
\text { hierarchies and divisions. }\end{array}$ \\
\hline & Dedicated teams for BPM & $\begin{array}{l}\text { No internal structures or } \\
\text { specialist departments. }\end{array}$ & $\begin{array}{l}\text { Specific contacts for the } \\
\text { planning and optimization of } \\
\text { business processes. }\end{array}$ & $\begin{array}{l}\text { BPM is performed by } \\
\text { specialized personnel } \\
\text { structured in teams. }\end{array}$ & $\begin{array}{l}\text { Distributed process managers } \\
\text { and a central process } \\
\text { management is operated. }\end{array}$ \\
\hline \multirow{4}{*}{$\begin{array}{l}\text { Infrastructure } \\
\text { and Data }\end{array}$} & Enterprise software systems & $\begin{array}{l}\text { Simple control system } \\
\text { architectures (PLCs, } \\
\text { SCADA) enabling } \\
\text { networked data } \\
\text { communication. } \\
\end{array}$ & $\begin{array}{l}\text { ERP systems are responsible } \\
\text { for integrated management of } \\
\text { main business processes. }\end{array}$ & $\begin{array}{l}\text { Systems, such as MES and } \\
\text { BPMS for sharing } \\
\text { information and obtaining } \\
\text { real-time feedback from } \\
\text { functional areas. }\end{array}$ & $\begin{array}{l}\text { Systems including interfaces } \\
\text { to each other that provide } \\
\text { automated decision-making } \\
\text { and data management. }\end{array}$ \\
\hline & Networking & $\begin{array}{l}\text { Basic wired (LAN) and } \\
\text { wireless (Wi-Fi) } \\
\text { networking technologies } \\
\text { covering most of the } \\
\text { enterprise facilities. } \\
\end{array}$ & $\begin{array}{l}\text { Basic and more advanced } \\
\text { technologies such as } 2 \mathrm{G} / 3 \mathrm{G} / 4 \mathrm{G} \\
\text { and Bluetooth and covering all } \\
\text { enterprise facilities. }\end{array}$ & $\begin{array}{l}\text { Basic and more advanced } \\
\text { technologies such as low- } \\
\text { energy PAN communication } \\
\text { protocols, e.g. ZigBee, BLE } \\
\text { or LoRa, are existing. }\end{array}$ & $\begin{array}{l}\text { Enhanced mobile broadband, } \\
\text { massive machine } \\
\text { communications, and ultra- } \\
\text { reliable low-latency } \\
\text { communications are existing. }\end{array}$ \\
\hline & Data processing & $\begin{array}{l}\text { Data can be stored, and } \\
\text { simple processing is } \\
\text { performed. }\end{array}$ & $\begin{array}{l}\text { IoT is capable of aggregating } \\
\text { data into simple context data. }\end{array}$ & $\begin{array}{l}\text { Aggregation of data into } \\
\text { complex context data. } \\
\text { Techniques for ensuring data } \\
\text { quality are applied. }\end{array}$ & $\begin{array}{l}\text { High-frequency event data } \\
\text { from heterogenous sources } \\
\text { can be processed. Complex } \\
\text { event processing is applied. }\end{array}$ \\
\hline & $\begin{array}{l}\text { Data analytics \& } \\
\text { interpretation }\end{array}$ & $\begin{array}{l}\text { Data analytics is sparsely } \\
\text { implemented. }\end{array}$ & $\begin{array}{l}\text { Basic analysis of IoT data is } \\
\text { conducted. IoT data analytics is } \\
\text { still mainly ad hoc. }\end{array}$ & $\begin{array}{l}\text { Analyses based on } \\
\text { calculations and co-relations. } \\
\text { Patterns based on rules. }\end{array}$ & $\begin{array}{l}\text { Predictive analytics is } \\
\text { performed using IoT data. }\end{array}$ \\
\hline \multirow{3}{*}{$\begin{array}{l}\text { Business Process } \\
\text { Management }\end{array}$} & Alignment \& methods & $\begin{array}{l}\text { Jobs and organizational } \\
\text { structures include a } \\
\text { process aspect but remain } \\
\text { basically traditional. } \\
\end{array}$ & $\begin{array}{l}\text { Broad process jobs and } \\
\text { structures are put in place } \\
\text { outside of traditional functions. }\end{array}$ & $\begin{array}{l}\text { Process measures and BPM } \\
\text { are deeply embedded in the } \\
\text { organization. }\end{array}$ & $\begin{array}{l}\text { Advanced process practices } \\
\text { that allow transfer of } \\
\text { responsibilities without legal } \\
\text { ownership. }\end{array}$ \\
\hline & $\begin{array}{l}\text { Process performance } \\
\text { controlling }\end{array}$ & $\begin{array}{l}\text { Absence of defined } \\
\text { metrics. }\end{array}$ & Basic cost and quality metrics. & $\begin{array}{l}\text { Metrics have been derived } \\
\text { from the enterprise's strategic } \\
\text { goals including time, cost, } \\
\text { quality, and flexibility. }\end{array}$ & $\begin{array}{l}\text { Managers review and refresh } \\
\text { the process metrics and } \\
\text { targets and use them in } \\
\text { strategic planning. }\end{array}$ \\
\hline & Process documentation & $\begin{array}{l}\text { Processes are not } \\
\text { structured and lack clear } \\
\text { definitions. }\end{array}$ & $\begin{array}{l}\text { Documentation is primarily } \\
\text { functional, but it identifies the } \\
\text { interconnections among } \\
\text { process entities. }\end{array}$ & $\begin{array}{l}\text { Description of interfaces with } \\
\text { other processes and enterprise } \\
\text { systems as well as the data } \\
\text { architecture. }\end{array}$ & $\begin{array}{l}\text { An electronic representation } \\
\text { of the process design supports } \\
\text { process reconfigurations. }\end{array}$ \\
\hline \multirow[b]{2}{*}{$\begin{array}{l}\text { IoT Application } \\
\text { Maturity }\end{array}$} & IoT architecture & $\begin{array}{l}\text { If any, the organization } \\
\text { adopts a basic IoT layer } \\
\text { architecture. }\end{array}$ & $\begin{array}{l}\text { Middleware layer that enables } \\
\text { interoperability and device } \\
\text { technology independence. }\end{array}$ & $\begin{array}{l}\text { Management of scalability } \\
\text { and interoperability. }\end{array}$ & $\begin{array}{l}\text { IoT architecture is prepared to } \\
\text { be reused in different } \\
\text { applications within the } \\
\text { company. }\end{array}$ \\
\hline & IoT technology & $\begin{array}{l}\text { Possibly some use of } \\
\text { RFID or sensors, but with } \\
\text { limited functionality. }\end{array}$ & $\begin{array}{l}\text { IoT technologies using existing } \\
\text { wired and wireless networking. } \\
\text { Cloud computing for vertical } \\
\text { communication. }\end{array}$ & $\begin{array}{l}\text { Assets and products } \\
\text { communicate horizontally and } \\
\text { directly within a closed } \\
\text { environment. }\end{array}$ & $\begin{array}{l}\text { The volume of generated data } \\
\text { and the processes that are } \\
\text { involved in the handling of } \\
\text { data become critical and } \\
\text { important to manage. }\end{array}$ \\
\hline \multirow{3}{*}{$\begin{array}{l}\text { IoT Integration } \\
\text { into Business } \\
\text { Processes }\end{array}$} & System integration & $\begin{array}{l}\text { If any, monitoring and } \\
\text { visualization purposes are } \\
\text { in focus. }\end{array}$ & $\begin{array}{l}\text { IoT supports some repeatable } \\
\text { tasks within certain business } \\
\text { processes. }\end{array}$ & $\begin{array}{l}\text { IoT is used for process control } \\
\text { using high-frequency event } \\
\text { data. }\end{array}$ & $\begin{array}{l}\text { IoT is successfully integrated } \\
\text { within each phase in the } \\
\text { management of processes. }\end{array}$ \\
\hline & $\begin{array}{l}\text { Behavioral and } \\
\text { organizational impact }\end{array}$ & $\begin{array}{l}\text { IoT has no impact on the } \\
\text { behavioral and } \\
\text { organizational } \\
\text { perspectives. }\end{array}$ & $\begin{array}{l}\text { IoT data is used to ensure } \\
\text { correct process sequences by, } \\
\text { e.g., detecting process task } \\
\text { deviations. }\end{array}$ & $\begin{array}{l}\text { IoT applications are able to } \\
\text { distribute process tasks along } \\
\text { process entities. }\end{array}$ & $\begin{array}{l}\text { The IoT system is responsible } \\
\text { to effectively allocate process } \\
\text { tasks, manage process entity } \\
\text { interactions, and guarantee } \\
\text { efficient process workflows. }\end{array}$ \\
\hline & $\begin{array}{l}\text { Functional and operational } \\
\text { impact }\end{array}$ & $\begin{array}{l}\text { IoT is not influencing the } \\
\text { actual process activities } \\
\text { and its execution. }\end{array}$ & $\begin{array}{l}\text { Process activities are changed } \\
\text { and improved by implementing } \\
\text { IoT technology. }\end{array}$ & $\begin{array}{l}\text { Process task execution is } \\
\text { directly influenced by } \\
\text { providing user interfaces. }\end{array}$ & $\begin{array}{l}\text { Process activities and } \\
\text { interactions with process } \\
\text { entities are redesigned by } \\
\text { integrating IoT. }\end{array}$ \\
\hline
\end{tabular}


Table 3. Translation Metric

\begin{tabular}{lccccc}
\hline \multirow{2}{*}{ Capability Dimension } & \multicolumn{5}{c}{ Required Capability } \\
& $\mathbf{1}$ & $\mathbf{2}$ & $\mathbf{3}$ & $\mathbf{4}$ & $\mathbf{5}$ \\
\hline IoT vision & 1 & 2 & 2 & 3 & 4 \\
\hline Decision making & 1 & 2 & 3 & 3 & 4 \\
\hline Technology affinity & 1 & 2 & 3 & 4 & 4 \\
\hline Continuous improvement culture & 1 & 2 & 3 & 4 & 4 \\
\hline Interdisciplinary, interdepartmental & 1 & 1 & 2 & 3 & 4 \\
collaboration & 1 & 1 & 2 & 3 & 4 \\
\hline Knowledge management & 1 & 2 & 3 & 4 & 4 \\
\hline IoT competences along employees & 1 & 2 & 3 & 4 & 4 \\
\hline Dedicated teams for IoT & 1 & 1 & 2 & 3 & 4 \\
\hline Dedicated teams for BPM & 1 & 2 & 3 & 3 & 4 \\
\hline Enterprise software systems & 1 & 2 & 3 & 3 & 4 \\
\hline Networking & 1 & 2 & 3 & 4 & 4 \\
\hline Data processing & 1 & 2 & 3 & 4 & 4 \\
\hline Data analytics \& interpretation & 1 & 2 & 3 & 3 & 4 \\
\hline Alignment \& methods & 1 & 2 & 3 & 3 & 4 \\
\hline Process performance controlling & 1 & 2 & 3 & 4 & 4 \\
\hline Process documentation & 1 & 1 & 2 & 3 & 4 \\
\hline IoT architecture & 1 & 2 & 2 & 3 & 4 \\
\hline IoT technology & 1 & 2 & 2 & 3 & 4 \\
\hline System integration & 1 & 2 & 3 & 3 & 4 \\
\hline Behavioral and organizational impact & 1 & 2 & 3 & 3 & 4 \\
\hline Functional and operational impact & & & & \\
\hline & & 1 &
\end{tabular}

For example, to achieve maturity level 2 , amongst others, the capability dimension IoT vision requires capability level 2 . Within the capability matrix of Table 2 , the information about this specific capability level can be found. As the capability matrix comprises all relevant capabilities, the MM follows a prescriptive approach, which allows the derivation of roadmaps and agendas.

\section{Discussion and Conclusion}

As the integration of IoT technology into existing business processes constitutes a major challenge for organizations, the proposed MM may be used to determine the status quo regarding necessary capabilities. Industrial organizations can therefore assess their readiness to effectively exploit IoT value propositions. Considering the lack of existing MMs, this paper contributes to the resolution of existing research gaps and tackles the formulated RQs. The MM has been developed according to the framework of Becker et al. [8] which enables a rigorously designed and evaluated model. At first an initial MM has been created based on an extensive literature review on existing MMs of both areas IoT and BPM respectively BPI. The findings were used to identify relevant capabilities and capability dimensions. The initial MM consisted of 100 capabilities aligned to 25 capability dimensions and four capability levels. In addition, five maturity levels have been formulated. To refine the initial MM, a six-round Delphi study has been performed with an expert panel consisting of 15 persons from industry and academia.
The final MM is composed of 21 capability dimensions including 84 capabilities along four capability levels.

Due to the nature of the applied methodology, this contribution is not without limitations. Although the literature review has been rigorously performed, the incorporated literature does not represent all existing work of that research area. Moreover, the selection of appropriate capabilities and dimensions can only cover a limited amount of all existing possibilities. Further, the success of a Delphi study highly relies on the expertise of the respondents [42]. Whilst we tried to arrange an appropriate expert panel, the selection of different experts may have led to different results. Furthermore, the technological capabilities of Table 2 could change over time as technology progresses. Therefore, the MM itself needs to be adapted periodically. Finally, the MM has not received practical assessment and therefore a final evaluation. Therefore, steps 5 to 8 of the framework will be addressed within future research.

In conclusion, the IoT-based BPI MM constitutes a valuable tool for organizations to assess their capabilities and create concrete plans for actions. Future research should focus on methods and frameworks to keep the MM assessment updated within organizations. This is highly relevant, as internal capabilities may change over time.

\section{References}

[1] A. Bayere, T. Heikki, V. Venkatesh, et al., "Internet of Things (IoT) - A Research Agenda for Information Systems", Commun. Assoc. Inf. Syst., vol. 45, 2020.

[2] L. Wessel, A. Baiyere, R. Ologeanu-Taddei, et al., „Unpacking the Difference Between Digital Transformation and IT-Enabled Organizational Transformation”, J. Assoc. Inf. Syst., vol. 22, no. 1, 2021.

[3] C. Janiesch, A. Koschmider, M. Mecella, et al., „The Internet of Things Meets Business Process Management: A Manifesto", IEEE Trans. Syst. Man Cybern. Syst., vol. 6, no. 4, pp. 34-44, 2020.

[4] M. Dumas, M. La Rosa, J. Mendling, and H. Reijers, Fundamentals of Business Process Management, Springer Verlag, Berlin, Heidelberg, 2018.

[5] P. Sethi, and S.R. Sarangi, "IoT: Architectures, Protocols, and Applications", J. Electr. Comput. Eng., vol. 2017, pp. $1-25,2016$

[6] A. Schumacher, S. Erol, and W. Sihn, "A Maturity Model for Assessing Industry 4.0 Readiness and Maturity of Manufacturing Enterprises", Procedia CIRP, vol. 52, pp. 161-166, 2016.

[7] K. Lichblau, V. Stich, M. Bertenrath, et al., "IMPULS Industrie 4.0-Readiness“, Impuls-Stiftung, Köln, 2015.

[8] J. Becker, R. Knackstedt, and J Pöppelbuß, "Developing MMs for IT Management", BISE, vol. 1, pp. 213-222, 2009.

[9] J. Pöppelbuß, and M. Röglinger, "What Makes a Useful Maturity Model? A Framework of General Design Principles for Maturity Models and its Demonstration in 
Business Process Management", 28 $8^{\text {th }}$ European Conference on Information Systems, 2011.

[10] M. Kohlegger, R. Maier, and S. Thalmann, "Understanding maturity models results of a structured content analysis", $5^{\text {th }}$ International Conference on Semantic Systems, pp. 61-61, 2009.

[11] M. Bertolini, G. Esposito, M. Neroni, and G. Romagnoli, "Maturity Models in Industrial Internet: a Review", Procedia Manuf., vol. 39, pp. 1845-1863, 2019.

[12] R. Minerva, A. Biru, and D. Rotondi, "Towards a definition of the Internet of Things (IoT)", IEEE, New York, 2015.

[13] L. Atzori, A. Iera, and G. Morabito, "The Internet of Things: A survey", Comput. Netw., vol. 54, no. 15, pp. 2787-2805, 2010.

[14] I.C.L. Ng, and S.Y.L. Walkenshaw, "The Internet-ofThings: Review and research directions", Int. J. Res. Mark., vol. 34, no. 1, pp. 3-21, 2017.

[15] S. Coksun, H. Basligil, and H. Baracli, "A weakness determination and analysis model for business process improvement", Bus. Process Manag. J., vol. 14, no. 2, pp. 243-261, 2008.

[16] J. Barney, "Firm Resources and Sustained Competitive Advantage", Journal of Management, vol. 17, no. 1, pp. 99-120, 1991.

[17] H. Wade, and J. Hulland, "Review: The Resource-Based View and Information Systems Research: Review, Extension, and Suggestions for Future Research", $M I S Q$, Vol. 28 No. 1, pp. 107-142, 2004.

[18] B. Häckel, R. Huber, B. Stahl, and M. Stöter, "Becoming a Product-Service System Provider - A Maturity Model for Manufacturers", $13^{\text {th }}$ International Conference on Wirtschaftsinformatik, 2021

[19] S.G. Day, "The Capabilities of Market-Driven Organizations", Journal of Marketing, vol. 58, no. 4, pp. 37-52, 1994.

[20] I. Dierickx, and K. Cool, "Asset Stock Accumulation and Sustainability of Competitive Advantage", Management Science, vol. 35, no. 12, pp. 1415-1524, 1989.

[21] T. De Bruin, M. Roseman, R. Freeze, and K. Uday, "Understanding the Main Phases of Developing a Maturity Assessment Model", 16 ${ }^{\text {th }}$ Australasian Conference on Information Systems, pp. 8-19, 2005.

[22] E. Serral, C.V. Stede, and F. Hasić, "Leveraging IoT in Retail Industry: A Maturity Model", $22^{\text {nd }}$ Conference on Business Informatics, 2020.

[23] L.A. Lasrado, R. Vatrapu, and K.M. Andersen, "Maturity Models Development in IS Research: A Literature Review", in IRIS Selected Papers, vol. 6, 2015.

[24] M.C. Paulk, B. Curtis, M.B. Chrissis, and C.V. Weber, "Capability maturity model, version 1.1", IEEE Softw., vol. 10, no. 4, pp. 18-27, 1993.

[25] CMMI Product Team, "CMMI for Development, Version 1.3", Carnegie Mellon, 2010.

[26] B. Jæger, and L.L. Halse, "The IoT Technological Maturity Assessment Scorecard: A Case Study of Norwegian Manufacturing Companies”, 2017 International Conference on Advances in Production Management Systems, pp. 143-150, 2017.

[27] Q. Tan, Y. Tong, S. Wu, and D. Li, "Evaluating the Maturity of CPS in discrete manufacturing shop-floor: A group AHP method with fuzzy grade approach", Mechanics, vol. 24, no. 1, pp. 100-107, 2018.

[28] G. Schuh, R. Anderl, J. Gausemeier, M. ten Hompel, and W. Wahlster, Industrie 4.0 Maturity Index: Die digitale Transformation von Unternehmen gestalten, utzverlag, München, 2017.

[29] C. Klötzer, and A. Pflaum "Toward the Development of a Maturity Model for Digitalization within the Manufacturing Industry's Supply Chain", 50 ${ }^{\text {th }}$ Hawaii International Conference on System Sciences, 2017.

[30] C. Leyh, T. Schäffer, K. Bley, and S. Forstenhäusler, "SIMMI 4.0 - A Maturity Model for Classifying the Enterprise-wide IT and Software Landscape Focusing on Industry 4.0”, 2016 Federated Conference on Computer Science and Information Systems, pp. 1297-1302, 2016.

[31] M. Rosemann, and T. De Bruin, "Towards a Business Process Management Maturity Model", 13 ${ }^{\text {th }}$ European Conference on Information Systems, 2005.

[32] A. Tarhan, O. Turetken, and H.A. Reijers, "Business process maturity models: A systematic literature review", Inf. Softw. Technol., vol. 75, pp. 122-134, 2016.

[33] F. Koetter, A. Weisbecker, and T. Renner, "Business Process Optimization in Cross-Company Service Networks: Architecture and Maturity Model", 2012 Annual SRII Global Conference, 2012.

[34] A.R. Hevner, S.T. March, J. Park, and S. Ram, "Design Science in Information Systems Research", MIS $Q$, vol. 28, no. 1, pp. 75-105, 2004.

[35] J. vom Brocke, A. Simons, B. Niehaves, et al., "Reconstructing the Giant: On the Importance of Rigour in Documenting the Literature Search Process", $17^{\text {th }}$ European Conference on Information Systems, 2009.

[36] C. Stoiber, and S. Schönig, "Process-aware Decision Support Model for Integrating Internet of Things Applications using AHP”, $23^{\text {rd }}$ International Conference on Enterprise Information Systems, 2021.

[37] I. Boughzala, and G.-J. de Vreede, "A Collaboration Maturity Model: Development and Exploratory Application", 45 ${ }^{\text {th }}$ Hawaii International Conference on System Sciences, 2012.

[38] M. Hammer, "The Process Audit", Harvard Business Review, vol. 85, no. 4, pp.111-123, 2007.

[39] K. Joshi, A.V. Singar, and K.B. Akhilesh, "IoT in Retail", Akhilesh K., Möller D. (ed) Smart Technologies. Springer, Singapore, 2019.

[40] A. Lockamy, and K. Mccormack, "The development of a supply chain management process maturity model using the concepts of business process orientation", Supply Chain Manag. vol. 9, no. 4, pp. 272-278, 2004.

[41] S. Jabonski, and C. Bussler, Workflow Management: Modeling concepts, architecture and implementation. Cengage Learning EMEA, Andover, 1996.

[42] R. Loo, "The Delphi method: a powerful tool for strategic management", Policing: An International Journal, vol. 25, no. 4, pp. 762-769, 2002.

[43] C. Okoli, and S.D. Pawlowski, "The Delphi method as a research tool: an example, design considerations and applications", Inf. Manag., vol. 42, no. 1, pp. 15-29, 2004. 